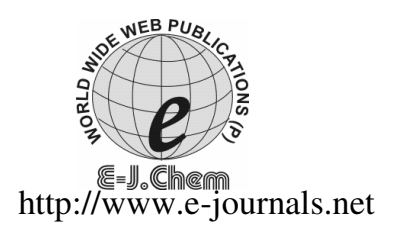

ISSN: 0973-4945; CODEN ECJHAO

E-Journal of Chemistry 2011, 8(4), 1588-1595

\title{
Removal of Direct Yellow 12 from Water Samples by Cloud Point Extraction Using Triton X-100 as Nonionic Surfactant
}

\author{
SHAHNAZ ABEDI and FARZIN NEKOUEI ${ }^{*}$ \\ Department of Chemistry, Gachsaran Branch, \\ Islamic Azad University, Gachsaran, Iran \\ *Young Researchers Club, Gachsaran Branch, \\ Islamic Azad University, Gachsaran, Iran \\ f.nekouei@hotmail.com
}

Received 9 December 2010; Accepted January 2011

\begin{abstract}
A surfactant mediated cloud point extraction (CPE) procedure has been developed to remove color from wastewater containing direct yellow 12 (Chrysophenine G), using triton x-100 (TX-100) as nonionic surfactant. The effects of the concentration of the surfactant, $\mathrm{pH}$, temperature and salt concentration on the different concentration of dye have been studied and optimum conditions were obtained for the removal of direct yellow 12 (DY 12). The concentration of DY 12 in the dilute phase was measured using UV-Vis spectrophotometer. It was found that the separation of phases was complete and the recovery of DY 12 was very effective in the presence of $\mathrm{NaCl}$ as an electrolyte. The results showed that up to $600 \mathrm{mg} \mathrm{L}^{-1}$ of DY 12 can quantitatively be removed $(>96 \%)$ by Cloud point extraction procedure in a single extraction using optimum conditions.
\end{abstract}

Keywords: Direct yellow 12 dye, Triton x-100, Cloud point extraction, Removal, Water samples

\section{Introduction}

Many industries, such as dyestuffs, textile, paper and plastics, use dyes in order to color their products and consume substantial volumes of water. As a result, they generate a considerable amount of colored wastewater. It is recognized that public perception of water quality is greatly influenced by the color ${ }^{1}$. The presence of very small amounts of dyes in water (less than $1 \mathrm{ppm}$ for some dyes) is highly visible and undesirable. Due to their good solubility, synthetic dyes are common water pollutants and they may frequently be found at trace quantities in industrial wastewater ${ }^{2}$. Direct yellow 12 (DY 12; molecular weight 680) is an azo dye and widely used in textile, paper and leather industries. This dye is also extensively used in cosmetics, food additives, ink and paint. The structure of the dye is shown in Figure 1. 


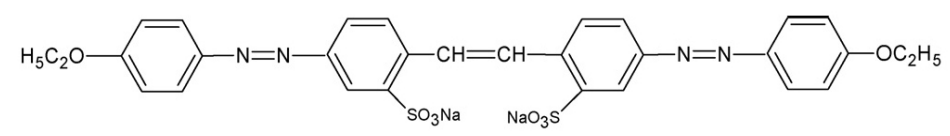

Figure 1. The structure of direct yellow 12

The effluent containing DY 12 is yellow in color, toxic and has high biological oxygen demand (BOD). The dye's strong color causes considerable damage to the aquatic life. DY 12 does not allow sunlight to pass through and thereby affects the photosynthesis of aquatic plants. Modern dyes are resistant to conventional biological treatment but these azo dyes are reduced to colorless primary amines by this treatment. These primary amines are even more toxic than the original dye ${ }^{3}$. Many investigators have studied different techniques for removal of colored dye from wastewater, e.g., micellar enhanced ultrafiltration (MEUF) ${ }^{4}$, various advanced oxidation processes ${ }^{5-6}$, ozonations ${ }^{7}$, nanofiltration ${ }^{8}$ and adsorption on to (i) sludge of wastewater treatment plant ${ }^{9}$ (ii) different bentonites ${ }^{10}$ (iii) various types of activated carbon ${ }^{11}$ and (iv) surfactant impregnated montmorillonite ${ }^{12}$, etc. Ultrafiltration (UF) and nanofiltration (NF) can be used for complete removal of all classes of dye, but care is needed to avoid membrane fouling which decreases the flux. Due to low biodegradability of dyes, a conventional biological wastewater treatment process is not very efficient in treating a dye wastewater ${ }^{13}$. Physical or chemical treatment processes are generally used to treat $\mathrm{it}^{14}$. The traditional techniques used for color removal are activated carbon (as adsorbent to remove dyes in wastewater), filtration and coagulation. Each method has few advantages and disadvantages. For example, the use of activated carbon (Charcoal) is technically easy but has high waste disposal cost. Coagulation using alums, ferric salts or limes is a low cost process, but all these methods have a major disadvantage of simply transferring the pollutants from one phase to another phase rather than destroying them. Biological treatment is a proven methods and cost effective.

In the last decade, increasing interest on the use of aqueous micellar solution has been found in the field of separation science ${ }^{15}$. The cloud point extraction (CPE) technique has also been used as a method for removal of dyes. The removal of color from wastewater containing Congo red ${ }^{16}$ and $\operatorname{eosin}^{17}$ has been performed by surfactant mediated cloud point extraction in batch mode using triton $\mathrm{x}-100$ as nonionic surfactant.

In this work, we have adopted cloud point extraction technique for the removal of DY 12 from wastewater using triton $\mathrm{x}-100$ as nonionic surfactant. The effects of temperature and equilibrium time, $\mathrm{pH}$, concentration of surfactant, dye and salt on the CPE of dye has been studied in order to establish optimum conditions.

\section{Experimental}

A Shimadzu Model 160A UV-Vis spectrophotometer was used for recording absorption spectra and absorbance measurements using $1 \mathrm{~cm}$ glass cells. A metrohm digital $\mathrm{pH}$ meter model 691 with a combined glass electrode measured the $\mathrm{pH}$. A thermostat bath model colora maintained at the desired temperature was used for the cloud point temperature (CPT) experiments. A 30 E 148 Sheme fan or Hettich centrifuge was used to accelerate the phase separation process.

All chemical used were of analytical grade and doubled distilled water was used throughout. A stock solution of $600 \mathrm{mg} \mathrm{L}^{-1}$ of DY 12 was prepared by dissolving $0.150 \mathrm{~g}$ of the reagent (Alvan Sabet Company, Iran) in water and diluting to $250 \mathrm{~mL}$ in a volumetric flask. 
The desired concentrations were obtained by successive dilutions. A measure of $0.3 \mathrm{~mol} \mathrm{~L}^{-1}$ of triton $\mathrm{x}-100$ (Aldrich) was prepared by dissolving $48.52 \mathrm{~g}$ in water and diluting to $250 \mathrm{~mL}$ in a volumetric flask. A $2.0 \mathrm{~mol} \mathrm{~L}^{-1}$ solution of sodium chloride was prepared by dissolving $11.68 \mathrm{~g}$ of $\mathrm{NaCl}$ (Merck) in water and diluting to $100 \mathrm{~mL}$ in a volumetric flask. A $2.0 \mathrm{~mol} \mathrm{~L}^{-1}$ solution of potassium chloride was prepared by dissolving $14.91 \mathrm{~g}$ of $\mathrm{KCl}$ (Merck) in water and diluting to $100 \mathrm{~mL}$ in a volumetric flask.

Britton-Robinson buffer solution in the $\mathrm{pH}$ range of 4 was made by mixing phosphoric acid $0.04 \mathrm{~mol} \mathrm{~L}^{-1}$, Acetic acid $0.04 \mathrm{~mol} \mathrm{~L}^{-1}$ and Boric acid $0.04 \mathrm{~mol} \mathrm{~L}^{-1}$ with appropriate volumes of $0.2 \mathrm{~mol} \mathrm{~L}^{-1}$ solution of sodium hydroxide ${ }^{18}$.

\section{General removal procedure}

An aliquot of the DY 12 solution, $10 \mathrm{~mL}$ of $2.0 \mathrm{~mol} \mathrm{~L}^{-1}$ of $\mathrm{NaCl}, 15 \mathrm{~mL}$ of $0.3 \mathrm{~mol} \mathrm{~L}^{-1}$ of triton $\mathrm{x}-100$ and $5 \mathrm{~mL}$ of Britton-Robinson buffer were added to a $50 \mathrm{~mL}$ volumetric flask and diluted to the mark with water. The resultant solution was transferred to a $50 \mathrm{~mL}$ tube and equilibrated at $75^{\circ} \mathrm{C}$ in a thermostat bath for $20 \mathrm{~min}$. Separation of the two phases was achieved by centrifuging for $10 \mathrm{~min}$ at $3500 \mathrm{rpm}$ and cooling in an ice bath for $5 \mathrm{~min}$. In this way, the bulk aqueous phase was easily decanted. The concentration of DY 12 in the dilute phase was measured by spectrophotometeric method.

\section{Analysis of dye in dilute phase}

A series of DY 12 solutions with different concentrations were prepared and their absorbance was measured at $403 \mathrm{~nm}$. A linear calibration graph was obtained in the range of $1.0-25 \mathrm{mg} \mathrm{L}^{-1}$ of DY 12 in aqueous solution. The equation of the regression line was $\mathrm{A}=0.0496 \mathrm{C}+0.0336$ with a correlation coefficient of $0.9991(\mathrm{C}$ is concentration of DY 12 as $\mathrm{mg} \mathrm{L}^{-1}$ ). This calibration equation was used to determine DY 12 concentration in dilute aqueous phase solution after removal of the dye by CPE in order to calculate the extraction efficiency.

\section{Results and Discussion}

For cloud point extraction, the efficiency of extraction is defined below:

Efficiency of extraction $=\left(1-\mathrm{C}_{\mathrm{d}} / \mathrm{C}_{0}\right) \times 100$

In which $\mathrm{C}_{0}$ and $\mathrm{C}_{\mathrm{d}}$ are the initial and dilute phase concentration of DY 12 , respectively. The absorption spectra of DY 12 showed a maximum absorption band at $403 \mathrm{~nm}$. Therefore, all the measurements were carried out at this wavelength. The effects of various operating conditions on the extent of dye separation have been investigated and the optimum concentrations have been established for CPE.

\section{Effect of initial $\mathrm{pH}$}

For this study, the effect of a pH range of 2-8 on the CPE of 20,50 and $100 \mathrm{mg} \mathrm{L}^{-1}$ of DY 12 was investigated. As can be seen in Figure 2, maximum efficiency was obtained at $\mathrm{pH} 4$. Therefore, this $\mathrm{pH}$ was chosen for further work. Different buffer systems with $\mathrm{pH} 4$ such as citrate, acetate, phthalate and Britton-Robinson were examined and Britton-Robinson buffer was selected as the optimum for subsequent experiments because it did not change the extraction efficiency of the solution after CPE. The effect of different volumes of BrittonRobinson buffer solution $(2-8 \mathrm{~mL})$ was investigated. The results showed that the extraction efficiency of the solution increased with buffer volume up to $4 \mathrm{~mL}$ and remained constant above that. Thus, $5 \mathrm{~mL}$ of Britton-Robinson buffer $\mathrm{pH} 4$ was added to the sample solutions to maintain the $\mathrm{pH}$ at 4 . 


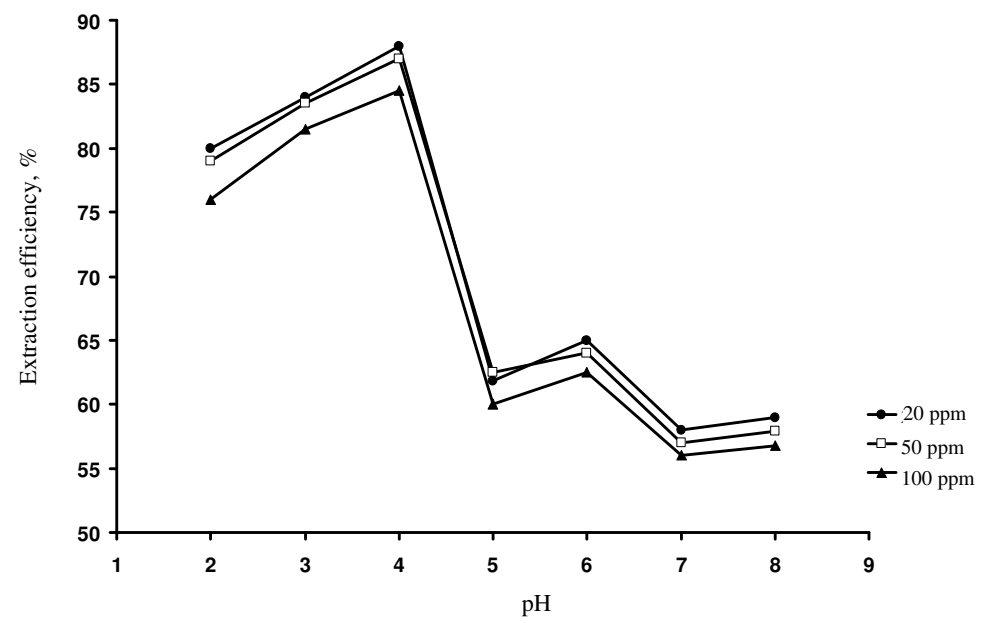

Figure 2. Effect of $\mathrm{pH}$ on removal of direct yellow 12 (Conditions: $50 \mathrm{~mL}$ of solution containing different concentration of dye (20,50 and $100 \mathrm{ppm}), 0.4 \mathrm{M}$ of $\mathrm{NaCl}$ and $0.09 \mathrm{M}$ of triton $\mathrm{x}-100$, equilibration temp $75{ }^{\circ} \mathrm{C}$ and equilibration time $20 \mathrm{~min}$, centrifuge time $10 \mathrm{~min}$ and centrifuge rates $3500 \mathrm{rpm})$.

\section{Effect of electrolyte concentration}

It has been shown that the presence of electrolytes can change the cloud point (CP) in different ways ${ }^{19}$. Salting-out electrolytes such as $\mathrm{NaCl}$ and $\mathrm{KCl}$ decrease the cloud point temperature, even by $30^{\circ} \mathrm{C}$. They can promote the dehydration of the ethoxy groups on the outer surface of the micelles, enhancing the micellar concentration leading to solubilization of more dye and resulting in a more efficient extraction ${ }^{20}$. Thus, the separation of the surfactant-rich phase can be obtained at lower temperatures, which is very important from practical point of view. Therefore, the effect of both potassium chloride and sodium chloride as electrolytes was studied. The results showed that when concentration of $\mathrm{KCl}$ or $\mathrm{NaCl}$ is increased, the extraction efficiency of DY 12 was increased only by few percent but both electrolytes decreased the cloud point temperature and our further experiments showed that less triton $\mathrm{x}-100$ is consumed when using $\mathrm{NaCl}$ as electrolyte. Thus, for this reason and because $\mathrm{NaCl}$ is more economical it was chosen as an electrolyte for further studies.

\section{Effect of triton $x$-100 concentration}

Several nonionic surfactant including triton $\mathrm{x}-114$, Triton $\mathrm{x}-100$ and PONPE 7.5 were tested for performing of CPE. Among them triton x-100 was chosen because of its higher extraction efficiency as well as its appropriate cloud point temperature as compared with other tested surfactants. The effect of the triton x-100 concentration on the removal of DY 12 is shown in Figure 3. As it is observed at a fixed temperature and feed dye concentration, the extraction efficiency of dye increases with surfactant concentration. The concentration of the micelles increases with surfactant concentration, resulting in more solubilization of dyes in the micelles. Since the surfactant concentration in the dilute phase remains around critical micelle concentration (CMC), the surfactant concentration along with the solubilized dye in the coacervate phase increases to maintain the material balance. Therefore, the extraction efficiency of dye increases with surfactant concentration. Quantitative removal of DY $12(>96 \%)$ was obtained when minimum $0.085 \mathrm{~mol} \mathrm{~L}^{-1}$ of triton $\mathrm{x}-100$ was used. The surfactant concentration of $0.09 \mathrm{~mol} \mathrm{~L}^{-1}$ was chosen as optimum. 


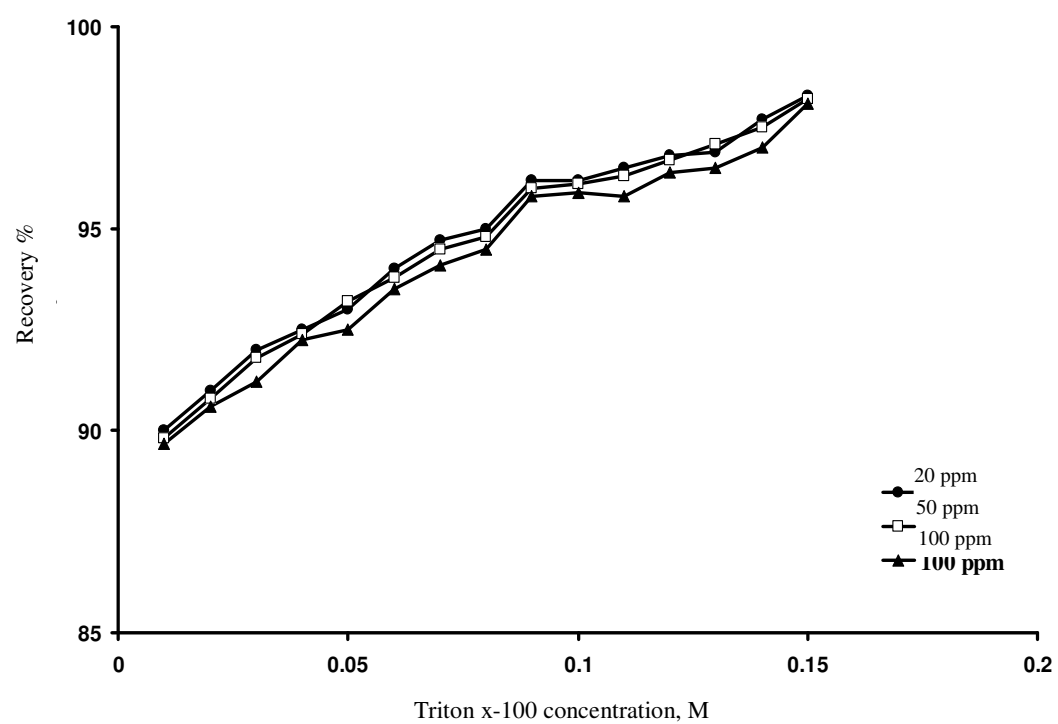

Figure 3. Effect of triton $\mathrm{x}-100$ on removal of direct yellow 12 (Conditions: $50 \mathrm{~mL}$ of solution containing different concentration of dye (20,50 and $100 \mathrm{ppm}), 0.4 \mathrm{M}$ of $\mathrm{NaCl}$ and $\mathrm{pH} \mathrm{4}$, equilibration temp $75^{\circ} \mathrm{C}$ and equilibration time $20 \mathrm{~min}$, centrifuge time $10 \mathrm{~min}$ and centrifuge rates $3500 \mathrm{rpm}$ ).

\section{Effect of temperature}

The solubilization capability of the micellar solution increases with temperature leading to an increase in the dye extraction. Therefore, the effect of operating temperature on the removal of dye was investigated. The results of the effects of the operating temperature on the extraction efficiency of dye indicated that the extraction of dye increases with temperature at different concentration of the dye $\left(20,50\right.$ and $\left.100 \mathrm{mg} \mathrm{L}^{-1}\right)$ up to a temperature of $75{ }^{\circ} \mathrm{C}$ and it is constant above that. Thus, temperature of $75{ }^{\circ} \mathrm{C}$ was used in further studies.

\section{Effect of equilibration time}

The dependence of extraction efficiency upon equilibration time was studied for a time interval of 5-30 min. Quantitative extraction efficiency values $(>96 \%)$ for different concentrations of the dye $\left(20,50\right.$ and $\left.100 \mathrm{mg} \mathrm{L}^{-1}\right)$ were obtained after $20 \mathrm{~min}$. An equilibration time of $20 \mathrm{~min}$ was chosen as an optimum value. The equilibration time required in the proposed cloud point procedure is only $20 \mathrm{~min}$ while the equilibration time (incubation time) required for other procedures using orange peel carbon is $120 \mathrm{~min}^{21}$, for $\mathrm{UV} / \mathrm{TiO}_{2}$ is $180 \mathrm{~min}^{22}$ and incubation period for mixed methanogenic culture is $300 \mathrm{~h}^{23}$.

\section{Effect of centrifuge time and rates}

It is often required to preconcentrate trace amounts of dye with high efficiency in a short time. The results indicated that centrifuging for $10 \mathrm{~min}$ at $3500 \mathrm{rpm}$ and cooling for $5 \mathrm{~min}$ in an ice-bath leading to the highest recovery of DY 12 dye.

\section{Effect of initial dye concentration}

The effect of initial dye concentration on the extraction efficiency using above optimum concentrations was investigated. The results presented in Table 1 show that for dye concentration 
of $1 \mathrm{mg} \mathrm{L}^{-1} 100 \%$ extraction efficiency is possible with triton $\mathrm{x}-100$ concentration of $0.09 \mathrm{~mol} \mathrm{~L}^{-1}$. For concentrations up to $600 \mathrm{mg} \mathrm{L}^{-1}$, direct yellow 12 quantitative removal $(>96 \%)$ is achieved by CPE procedure in a single extraction which is higher than some of the previously reported methods using orange peel carbon $^{21}$ and in the presence of $\mathrm{ZnO}$ catalyst $\mathrm{t}^{24}$.

The extraction efficiency decreases with increasing dye concentration at constant triton x-100 concentration. As can be observed in Figure 3, the extraction efficiency can be further improved $(>98 \%)$ by increasing triton $x-100$ concentration to $0.15 \mathrm{~mol} \mathrm{~L}^{-1}$. The dye uptake in this study was $600 \mathrm{mg} \mathrm{L}^{-1}$, which is higher than some of the previously reported procedures using orange peel carbon ${ }^{21}, \mathrm{UV} / \mathrm{TiO}_{2}{ }^{22}$ and $\mathrm{ZnO}$ catalyst ${ }^{24}$.

Table 1. Effect of initial dye concentration on the CPE efficiency of direct yellow 12

\begin{tabular}{cc}
\hline Concentration, $\mathrm{mg} \mathrm{L}^{-1}$, Efficiency $\%$ & ${ }^{\mathrm{a}} \mathrm{CPE}$ \\
\hline 1 & 100 \\
5 & 98.9 \\
10 & 97.0 \\
20 & 97.8 \\
50 & 97.2 \\
100 & 97.7 \\
150 & 97.1 \\
300 & 95.9 \\
600 & 96.1 \\
\hline
\end{tabular}

\section{Interference studies}

${ }^{a}$ CPE: Cloud point extraction

The effect of various ions as potential interference on the removal of DY 12 was investigated. Known concentrations of potential interfering ions were added to a solution containing $20 \mathrm{mg} \mathrm{L}^{-1}$ of DY 12 and the dilute phase solution was analyzed by the proposed method. The tolerance limit of each foreign ion substance was taken as largest concentrations yielding an error of less $\pm 5 \%$. The results presented in Table 2 show that very good selectivity is achieved. The interference of direct red and golden yellow as dye was also studied.

Table 2. The effect of foreign species on the determination of $20 \mathrm{mg} \mathrm{L}^{-1}$ of DY 12

\begin{tabular}{cc}
\hline Foreign species ratio, w/w & Tolerance \\
\hline $\mathrm{Na}^{+}, \mathrm{Cd}^{2+}, \mathrm{Mg}^{2+}, \mathrm{Ca}^{2+}, \mathrm{NH}_{4}^{+}, \mathrm{I}^{-}, \mathrm{Bi}^{+}$, & \\
$\mathrm{NO}_{2}{ }^{-}, \mathrm{Br}^{-}, \mathrm{F}^{-}, \mathrm{HPO}_{4}^{2-}, \mathrm{Zn}^{2+}, \mathrm{SO}_{3}^{2-}, \mathrm{Mn}^{2+}$ & 1000 \\
$\mathrm{Ag}^{+}, \mathrm{Sr}^{2+}, \mathrm{CH}_{3} \mathrm{COO}^{-}, \mathrm{Li}^{+}$ & \\
$\mathrm{Pb}^{2+}, \mathrm{SCN}^{-}, \mathrm{Ba}^{2+}$ & 800 \\
$\mathrm{Cu}^{2+}, \mathrm{CO}^{2+}, \mathrm{ClO}_{4}^{-}$ & 600 \\
$\mathrm{NO}_{3}^{-}, \mathrm{Al}^{3+}$ & 400 \\
$\mathrm{Fe}^{2+}$ & 200 \\
Direct Red (dye) & 70 \\
Golden Yellow (dye) & 30 \\
\hline
\end{tabular}

\section{Application to real samples}

In order to test the reliability of the proposed removal methodology, it was applied to the removal of concentrations of direct yellow 12 from domestic waste water, river water and 
industrial water samples. For this purpose, $15 \mathrm{~mL}$ of each of the samples was treated under the general procedure. Spiking DY 12 to the samples performed the validity of the procedure. The results presented in Table 3 show that good extraction efficiencies are obtained for the removal of DY 12 spiked to river water, industrial water and domestic waste water samples.

Table 3. Removal of direct yellow 12 in spiked water samples

\begin{tabular}{lcc}
\hline \multicolumn{1}{c}{ Sample } & Direct yellow 12 added $\mathrm{m} \mathrm{L}^{-1}$ & Extraction efficiency $^{\mathrm{a}}, \%$ \\
\hline Industrial water & 20 & $96.4 \pm 1.1$ \\
& 50 & $97.0 \pm 0.6$ \\
Domestic wastewater & 100 & $96.2 \pm 0.9$ \\
& 20 & $96.7 \pm 0.8$ \\
& 50 & $96.3 \pm 0.7$ \\
River water & 100 & $95.9 \pm 1.1$ \\
& 20 & $96.0 \pm 1.0$ \\
& 50 & $95.7 \pm 1.2$ \\
& 100 & $96.9 \pm 0.9$ \\
\hline
\end{tabular}

\section{Conclusion}

${ }^{a} x \pm t s / \sqrt{ } n$ at $95 \%$ confidence $(n=4),(t=3.18)$

Cloud point extraction was successfully applied to remove direct yellow 12 from wastewater using triton $\mathrm{x}-100$ as a nonionic surfactant. The extraction efficiency increased with temperature, surfactant and salt concentrations. From the experimental results, it was observed that for dye concentrations $1-600 \mathrm{mg} \mathrm{L}^{-1}$, quantitative recoveries $(>96 \%)$ is obtained in a single extraction. triton $\mathrm{x}-100$ is environmental friendly, only small amounts is used and can be recovered from the system by a simple extraction. The experimental requirements (time and preparation of material) are better than some of the previously reported methods ${ }^{21,25,26}$ for the removal of DY 12. The cloud point extraction procedure described above is straightforward while orange peel carbon requires pretreatments with chemical compounds for long times. Moreover, cloud point extraction strategy can easily be adopted for large-scale samples.

\section{Acknowledgment}

The authors wish to thank Islamic Azad University, Gachsaran branch, for financial support of this work.

\section{References}

1 Crini G, Bioresour Technol., 2005, 97(9), 1061-1085.

2 Papinutti L, Mouso N and Forchiassin F, Enzyme Microb Technol., 2006, 39, 848-853.

3 Glover B, J Soc Dyer Color, 1993, 109, 273.

4 Purkait M K, Dasgupta S and De S, Sep Purif Technol., 2004, 37, 81-92.

5 Shu H Y, Huang C R and Chang M C, Chemosphere, 1994, 29, 2597.

6 Marechal M L, Slokar Y M and Taufer T, Dyes Pigments, 1997, 33, 181-298.

7 Reynolds G, Graham N, Perry R and Rice R G, A review. Ozone Sci Eng., 1989, 11(4), 339-382.

8 Chakraborty S, Purkait M K, Dasgupta S, De S and Basu J K, Sep Purif Technol., 2003, 31, 141-351.

9 Davis L and Randal C, J Water Pollut Cont Fed., 1978, 5, 382-386.

10 Arvanitoyannis I, Eleftheriadis I and Tsatsaroni E, Chemosphere, 1989, 18, 1707-1711. 
11 Al-Degs Y, Khraisheh M A M, Allen S J and Ahmad M N A, Sep Sci Technol., 2001, 36(1), 91-96.

12 Jae-Hyun B, Dong-Ik S and Young-Woong J, Sep Sci Technol., 2000, 35(3), 353-365.

13 Seshadri S, Bishop P L and Agha A M, Waste Manage., 1994, 15, 127-137.

14 Banat I M, Nigam P, Singh D and Marchant R, A Review. Bioresource Technol., 1996, 58(3), 217-227.

15 Gullickson N D, Scamehorn J F and Harwell J H, Liquid-coacervate extraction. In: Scamehorn J F, Harwell H J, (Eds), Surfactant Based Separation Processes; Marcel Dekker Inc: New York, 1989, 139.

16 Purkait M K, Vijay S S, Dasgupta S and De S, Dyes Pigments, 2004, 63, 151-169.

17 Purkait M K, Banerjee S, Dasgupta S and De S, Water Res., 2005, 39, 3885-3890.

18 Britton H T K and Robinson R A, J Chem Soc., 1931, 458, 1456-1462.

19 Coelho L M and Arruda M A Z, Spectrochim Acta, 2005, 60B, 743-748.

20 Paleologos E K, Giokasm D L and Karayannis M I, Trends Analyt Chem., 2005, 24, 426-436.

21 Khaled A, Nemr A El, El-Sikaily A and Abdelwahab O, Desalination, 2009, 238, 210-232.

22 Toor A P, Verma A, Jotshi C K, Bajpai P K and Singh V, Dyes and Pigments, 2006, 68, 53-60.

23 Isık M and Sponza D T, Process Biochem., 2005, 40, 1053-1062.

24 Nageswara Rao A, Sivasankar B and Sadasivam V, J Mol Catal A: Chem., 2009, 306, 77-81.

25 Sohrabi M R and Ghavami M, Desalination, 2010, 252(1-3), 157-162.

26 Rathi A, Rajor H K and Sharma R K, J Hazard Mater., 2003, B102, 231-241. 


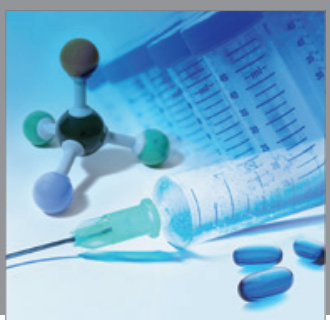

International Journal of

Medicinal Chemistry

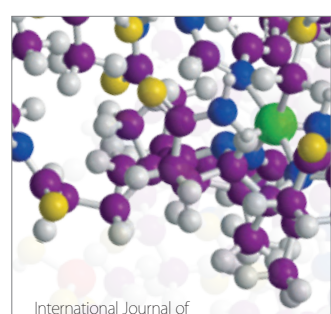

Carbohydrate Chemistry

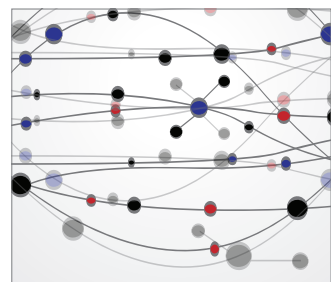

The Scientific World Journal
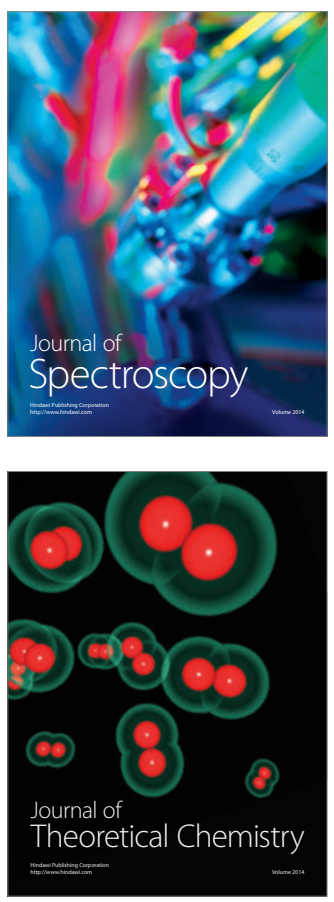
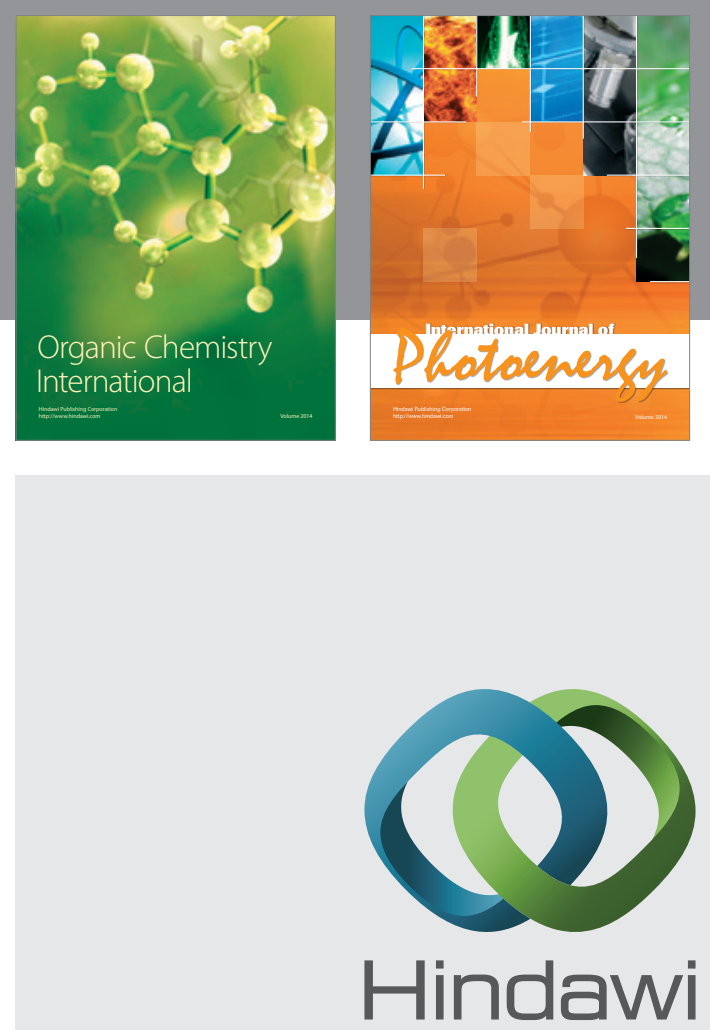

Submit your manuscripts at

http://www.hindawi.com
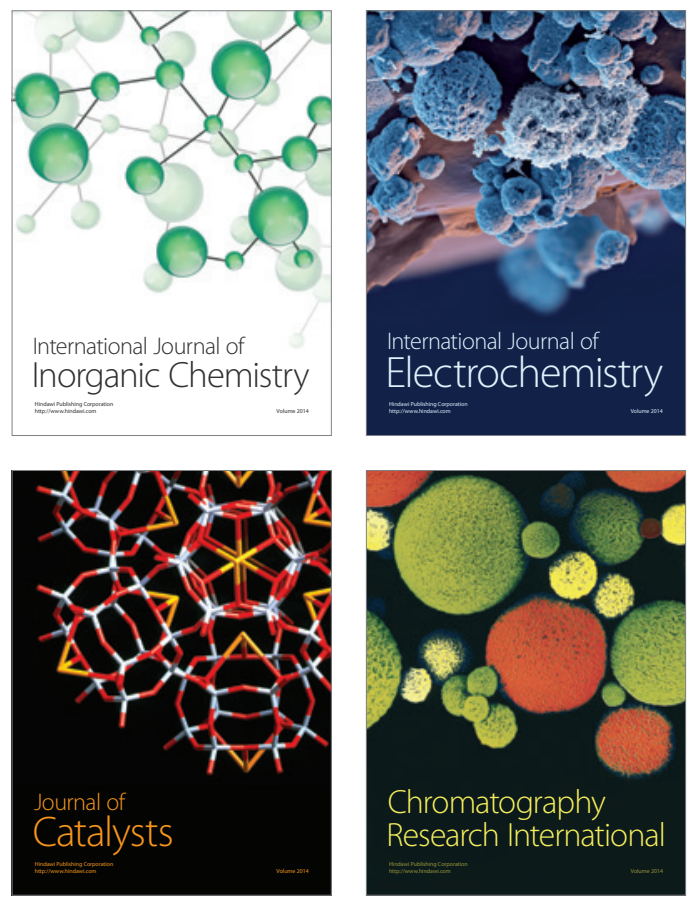
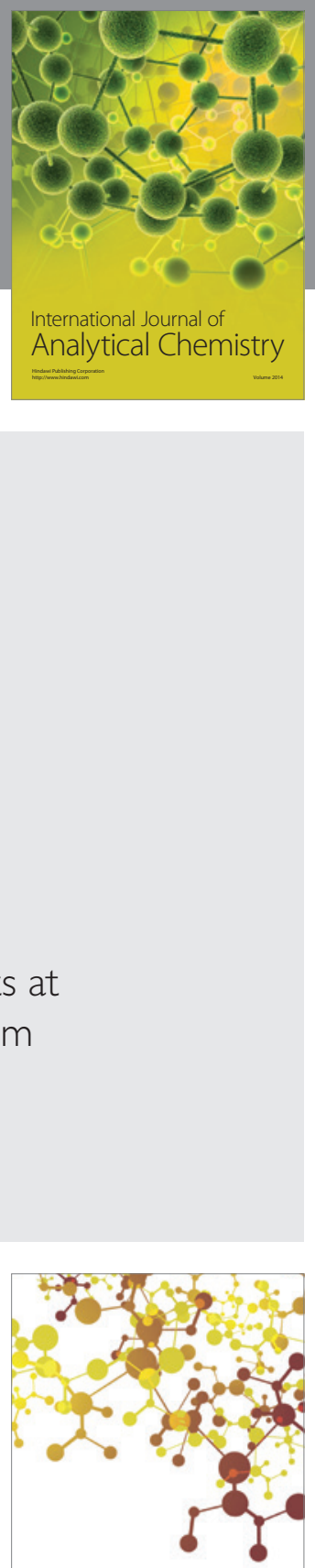

Journal of

Applied Chemistry
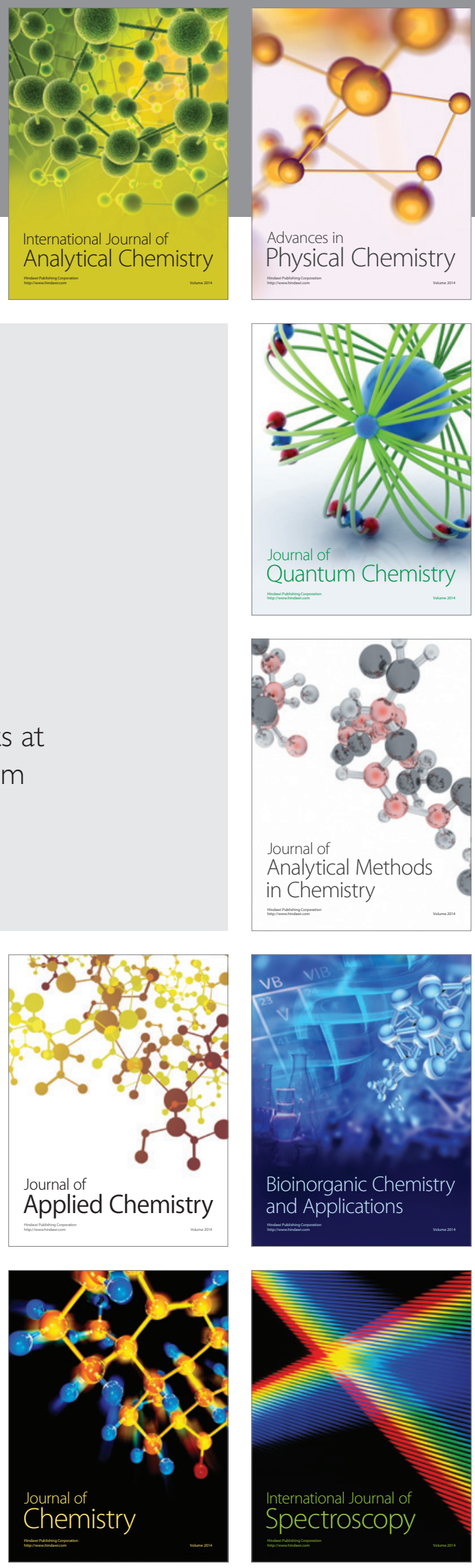